\title{
ARTIGO
}

\section{A semântica da complexidade e sua estrutura social: o materialismo "pós-estruturalista" da teoria dos sistemas}

\section{Pablo Holmes*}

\section{Resumo}

Este artigo explora a diferença entre estrutura e semântica como chave explicativa para as reivindicações da teoria dos sistemas acerca de suas vantagens como autodescrição sociológica da sociedade moderna. O argumento central é o de que a teoria dos sistemas se utiliza dessa diferença para explicar como estruturas sociais desencadeiam semânticas específicas. A relação entre estrutura social e semântica é mediada pela complexidade das estruturas. Nesse sentido, a teoria dos sistemas se distingue de teorias pós-modernas, do discurso ou do poder. Em lugar de constatar a pluralidade de narrativas e tirar daí consequências muitas vezes precipitadas acerca da contingência, como a centralidade do poder na reprodução social (um primado do "político"), a teoria dos sistemas insiste em um primado do social que aponta para as raízes estruturais da visibilidade dessa contingência. Isso torna a sociedade capaz de refletir sobre suas possibilidades a partir de uma teoria adequada à sua própria complexidade.

Palavras-chave: Teoria dos sistemas. Complexidade. Estrutura/semântica. Materialismo.

\footnotetext{
* Universidade de Brasília, Brasil.
} 


\title{
The semantics of complexity and its social structure: the "post-structuralist" materialism of systems theory
}

\begin{abstract}
In this article I look into the difference between structure and semantics as an explanatory key for the claims of systems theory about its advantages as a sociological self-description of modern society. The central argument is that systems theory resorts to this difference for explaining how social structures set in motion specific semantics. The relation between social structure and semantics is mediated by the complexity of the structures. In this sense, systems theory is distinguished from postmodern theories of discourse or power. Rather than establishing the plurality of narratives and inferring from it often hasty consequences regarding the contingency, such as the centrality of power in social reproduction, systems theory insists on a precedence of the social that points to the structural roots of the visibility of such contingency. This makes society able to reflect on its possibilities, based on a theory appropriate to its own complexity.
\end{abstract}

Keywords: Systems theory. Complexity. Structure/ semantics.

\section{Introdução}

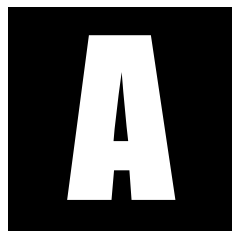

complexidade estrutural da sociedade se reflete em sua complexidade semântica. Ou, dito de outro modo, "a complexidade evolutivamente variável de uma sociedade produz correlatos semânticos nas suas respectivas dimensões de sentido" (Luhmann, 1980, p. 35). A teoria dos sistemas entende, assim, que existe uma relação entre a complexidade da sociedade e sua capacidade de produzir os artefatos semânticos com que descreve a realidade, inclusive a si própria. E, desse modo, ela segue uma tradição que remonta a Hegel e Marx e que compreende a teoria social como um produto reflexivo da sociedade que se propõe a descrever.

Diante disso, uma sociedade hipercomplexa como a sociedade moderna exige - e desencadeia -, para sua autocompreensão, uma semân- 
tica igualmente complexa ou, mais precisamente, uma teoria da complexidade social. A teoria dos sistemas quer ser exatamente essa teoria. Essa formulação, certamente um tanto abstrata, implica algumas decisões teóricas prévias que precisam ser explicitadas e que decerto podem parecer estranhas para aqueles pouco familiarizados com os meandros da teoria.

A seguir, eu gostaria de reconstruir as condições estruturais de uma teoria social da complexidade para a sociedade moderna por meio de uma diferença fundamental para a teoria dos sistemas: a diferença entre estrutura e semântica. Essa distinção é fundamental para desvendar questões epistemológicas de fundo, que relacionam a teoria social à teoria da complexidade, à teoria dos sistemas e à teoria da evolução. Nesse sentido, uma sociedade diferenciada funcionalmente e, portanto, hipercomplexa, só pode ser descrita por uma teoria que abra mão de pontos de vista últimos capazes de servir como critérios irrefutáveis de julgamento da realidade. Isso não quer dizer, porém, que a sociologia deva se perder numa incomensurabilidade de narrativas. Antes disso, para Luhmann, a teoria social deve ser uma teoria radicalmente apoiada na materialidade do "social", capaz de descrever a sociedade e a relação entre sua estrutura e sua semântica, levando em conta os processos concretos de sua reprodução. Isso tem implicações epistemológicas importantes. A mais relevante delas talvez seja a atenção que deve ter a sociologia à diversidade de lógicas distintas e infungíveis que operam no interior da sociedade moderna e a impossibilidade de simplificações que as suprimam. Nesse artigo, tentarei reconstruir a argumentação da teoria dos sistemas sociais segundo a sua pretensão de ser uma teoria da complexidade adequada à sociedade moderna, ou seja, uma teoria que descreve, de maneira semanticamente complexa, a complexidade estrutural da sociedade que torna possível sua própria existência enquanto teoria.

Na parte 1, irei expor a forma como Reinhardt Koselleck formula a distinção entre estrutura e semântica, a qual serve a Niklas Luhmann 
para a sua própria formulação. Depois, na parte 2, descreverei a recepção da distinção no interior da teoria dos sistemas, apontando que ela é interpretada a partir de uma posição claramente "pós-estruturalista". Com isso quero dizer que a teoria dos sistemas rompe com uma compreensão da distinção estrutura/semântica que a torne correlata à distinção realidade/linguagem ou da distinção sujeito/objeto, passando a compreender ambas como formas sociais de comunicação. Na parte 3, enfrentarei alguns problemas relativos a essa distinção no interior da teoria dos sistemas, sobretudo aqueles relativos ao que chamo uma compreensão "materialista" da diferença entre observação e operação. Ao final, na parte 4, interpretarei a distinção entre semântica e estrutura como o resultado de uma descrição sociológica fundada em uma teoria da complexidade social. De acordo com esse ponto de vista, a teoria social dos sistemas guardaria para si o papel de instância de observação que compreende a sociedade moderna como uma forma de comunicação que se reproduz a si mesma de acordo com diferentes formas de operação (o direito, a arte, a política, a economia, a ciência etc.) sem que nenhuma delas tenha preponderância definitiva no processo evolutivo. Uma tal teoria pode prevenir-nos, por exemplo, contra precipitações e simplificações teóricas como aquelas que reduzem o social a apenas uma de suas dimensões, seja ela ao político e à diferença amigo/inimigo, ao econômico e à diferença ter/não ter ou mesmo à ciência e à diferença verdade/falsidade.

\section{A diferença estrutura/semântica na História dos Conceitos de Reinhardt Koselleck}

A diferença entre semântica e estrutura, como formulada pela teoria dos sistemas, é tributária originalmente de uma recepção da história dos conceitos de Reinhard Koselleck (Luhmann, 1980, p. 13; Stichweh, 
2000; Stäheli, 2000, p. 186). Essa recepção conceitual foi, contudo, efetuada com numerosas adaptações e ressalvas. Enquanto a história dos conceitos compreende a semântica como um instrumental de pesquisa histórica, na teoria dos sistemas o conceito é mais abrangente, referindo-se a uma compreensão mais básica de todo e qualquer fenômeno social. Para compreender a distinção, assim como sua recepção e adequação no contexto de uma teoria da complexidade, é importante reconstruí-la em seus próprios termos.

Em 1972, Reinhardt Koselleck propôs, na introdução ao seu léxico "Geschichtliche Grundbegriffe", um programa de pesquisas históricas que rompia com a tradição idealista da história das palavras e a tradição orientada de modo materialista para os eventos históricos Kosellec (1972, p. $\mathrm{xx}$ ), ao mesmo tempo em que tentava não se confundir com a análise do discurso, que surgia como uma moda francesa Kosellec (1972, p. xxi). Segundo ele, a história dos conceitos deveria tratar de ambos os níveis - o da sociedade e o dos discursos -, relacionando-os, na medida em que realizava uma análise histórica crítica das palavras (historisch-kritische Wortanalyse), sem reduzir-se a apenas um deles. Essa pesquisa deveria ir além de uma interpretação dos conteúdos de significado de termos, levando em consideração ao mesmo tempo o papel dos discursos na constituição do processo histórico, compreendendo os diferentes usos das palavras em uma dimensão necessariamente diacrônica e com referência "às mudanças estruturais de longo prazo" em que estariam inseridas (Koselleck 1972, p. xxi). A pesquisa histórica se dedicaria, assim, à investigação de textos e documentos, observando o significado contextual e contencioso de conceitos como democracia, revolução, classe social etc. e o modo como eles expressam os contextos sociais em que surgem, condicionando também a própria realidade social. A história dos conceitos investigaria, assim, as implicações existentes entre "os eventos históricos sincrônicos e suas estruturas sociais diacrônicas" (Koselleck, 2006, p. 22). 
Para Koselleck, atos comunicativos ocorrem de modo indistinto e indivisível tanto em sua dimensão "pré-linguística" (vorsprachlich) como na linguística (2006, pp. 14-17). Não haveria, portanto, nada como um significado independente do uso que tem a palavra. Nem seria possível um estudo semântico de palavras que isolasse seu significado dos contextos em que essas são utilizadas. Entretanto, embora as palavras sejam plurívocas, é possível localizar o que uma palavra significa univocamente, tão logo ela seja utilizada em um determinado contexto social e histórico Kosellec (1972, p. xxii). Nesse ponto, ele introduz uma distinção entre palavras e conceitos. E, para ele, com os conceitos, as coisas se passariam de forma um pouco diferente. Seria possível isolar analiticamente os conceitos e refletir a sua plurivocidade de sentidos, mas um conceito permanece multívoco também nos contextos sociais em que é utilizado: "ele se prende à palavra que o carrega, mas é, ao mesmo tempo, muito mais do que ela", pois uma palavra só se torna um conceito, "se os elementos de um contexto político-social no qual e para o qual essa palavra é utilizada se tornam presentes nela", tornando-a um índice da estrutura histórica (Koselleck, 1972, p. xxii).

A observação analítica de conceitos começa, assim, sempre com uma análise das palavras que, por meio do estabelecimento de sua relação com os eventos compreendidos desde a perspectiva de uma história social, revelam seu significado como "conceito" (Koselleck, 1972, p. xxiii). Os conceitos seriam, por sua vez, "concentrados de muitos conteúdos de significado" que explicitam o caráter diacrônico de sua respectiva estrutura social, com suas contingências e disputas políticas (Koselleck, 1989, p. 120). Eles trazem em si a luta ideológica pelas estruturas sociais em seus respectivos tempos históricos, servindo como o índice dos conflitos históricos concretos (estruturais).

Mas eles não funcionam apenas como uma "superestrutura" social (Überbau). Concedendo certa razão às teorias do discurso, Koselleck entende que os conceitos funcionam também como condição de pos- 
sibilidade semântica dada antecipadamente aos eventos históricos: eles selecionam as possibilidades estruturais que podem se efetivar, pois eles concebem a realidade à medida que lhe emprestam significado. Isso se torna visível, por exemplo, no campo da política, quando um conceito de dominação não apenas expressa uma forma de organização política, como a constitui. "Uma unidade política ou social se constitui apenas mediante conceitos, por meio dos quais ela se define a si própria e em oposição a outras" (Koselleck, 1979, p. 212). A linguagem social cristalizada em conceitos seria mais do que um índice semântico de experiências históricas, consistindo, também, em uma acumulação de sentidos que se sedimenta em uma semântica, a qual retroalimenta a ação histórica.

Os conceitos conteriam ambiguidades aproveitadas pelos próprios agentes históricos em sua ação. As semânticas seriam, assim, o meio no qual os eventos históricos se expressam e se realizam, assim como condicionamentos conceituais dos eventos possíveis. Agentes sociais e acontecimentos "só podem se expressar nos quadros da linguagem concreta" (Koselleck, 2006, p. 42), assim, "as repetibilidades linguísticas (sprachliche Wiederholbarkeiten) e a sequência intransponível (unüberholbare Sequenz) dos eventos caracterizam estruturas temporais discerníveis entre si", que se expõem ao estudo de uma história dos conceitos (geschitliche Grundbegriffe) (Koselleck, 2006, p. 41). Koselleck diferencia, assim, dois níveis de análise: o semântico, que seria o nível acessível à investigação histórica por meio dos próprios conceitos, e o estrutural, que consiste na observação das estruturas sociais nas quais os conceitos emergem, para as quais eles servem como índices e, ao mesmo tempo, condição limitadora.

Embora bastante rica teoricamente, a formulação de Koselleck não é isenta de problemas. A sua compreensão da relação entre a sequência dos eventos históricos e as semânticas em que eles se expressam (os conceitos) revela uma distinção entre uma história real (a dos eventos) e 
uma história dos conceitos (a semântica) que dificilmente se sustenta nas atuais condições de reflexão da teoria social. De fato, se para a história dos conceitos não há qualquer história que possa ser descrita para além da linguagem disponível à comunidade de historiadores, permanece havendo uma dimensão que está além desta (Koselleck, 2006, p. 32). Afinal, "o que pode ser concebido e o que precisa ser concebido em conceitos reside fora dos próprios conceitos" (Koselleck, 2006, p. 61).

Koselleck insiste expressamente em uma diferença entre a realidade, que se torna cognoscível por meio de conceitos, e a linguagem na qual os conceitos são mantidos e articulados. Contra o giro linguístico radical da ciência histórica e claramente contra a tentação de reduzir a historiografia à análise do discurso, Koselleck acusa "todas as teorias atuais da moda que reduzem a realidade à linguagem e a nada mais" de ignorarem o fato de que "a linguagem é e permanece ambígua" em relação aos eventos (2006, p. 61). De um lado, "ela registra - receptivamente - o que é o caso fora dela", ou seja, ela afirma o que se impõe a ela; por outro lado, ela se comporta de modo produtivo frente ao seu mundo exterior, na medida em que tudo que se experimenta e se conhece é trazido a conceitos constituídos na linguagem (Koselleck, 2006, p. 62). Desse modo, porém, Koselleck produz dois níveis ontológicos distintos que, embora se relacionem, deixam a sociedade separada do texto que a descreve (Stäheli, 2000, p. 196).

De modo bastante diferente, a teoria dos sistemas concebe as estruturas sociais, a realidade social, a história e a semântica - a sociedade, portanto - como comunicação, ou seja, como operações que se dão no meio sentido. Luhmann não se arrisca a dizer que não exista uma realidade. Segundo ele, "há fortes razões para crermos que, caso a realidade que permanece totalmente desconhecida fosse totalmente entrópica, não poderia haver qualquer conhecimento" Luhmann (1988, p. 41). Ainda assim, como 
os sistemas sociais operam autorreferencialmente, quer dizer, em exclusivo autocontato (Luhmann, 1987, p. 59), a realidade jamais pode ser conhecida diretamente, servindo ao conhecimento apenas como uma suposição necessária, e como tal construída no meio que é a própria comunicação.

Torna-se, assim, no mínimo contraintuitivo partir de uma distinção radical entre linguagem e realidade para compreender a diferença estrutura/semântica no interior da teoria dos sistemas. Mesmo que a realidade e a linguagem se distingam, essa distinção opera exclusivamente no meio sentido: ela é uma distinção da própria comunicação (Luhmann, 1997, p. 213, p. 614). Luhmann aponta, assim, que falta à História dos Conceitos uma perspectiva que só pode ser oferecida por uma teoria da sociedade que entenda a narrativa dos eventos como uma parte da sociedade que comunica a si mesma enquanto se autodescreve por meio de conceitos (1980, p. 18). Para ele, a diferença pode ser mantida, mas necessita de uma reespecificação capaz de livrá-la de quaisquer resquícios de ontologização pré-construtivistas.

\section{Estrutura e semântica na teoria dos sistemas: uma distinção pós-estruturalista?}

Na teoria dos sistemas, o conceito de "semântica" serve inicialmente para indicar uma condensação e uma confirmação do sentido, dada por meio da sua repetição e sua estabilização na forma de expectativas dotadas de certa generalidade (Luhmann, 1997, p. 46). Para Niklas Luhmann, a "reprodução de sentido é garantida já pelas palavras da língua" (Luhmann, 1997, p. 47), que servem como meio desacoplado surgido evolutivamente para a fixação do sentido.

Como um sistema social não passa de uma contínua reprodução operativo-recursiva de eventos de sentido, não existe semântica sem que haja estruturas a tornar razoavelmente provável a manutenção da ope- 
ratividade do sistema. A semântica é, ao mesmo tempo o resultado da permanência de determinada estrutura social e aquilo que torna provável sua permanência. Ao mesmo tempo, semânticas compostas por palavras são reais apenas graças à ação social que as atualiza (Luhmann, 1980, p. 20). Se não houvesse ações sociais, não haveria estruturas e, logo, qualquer semântica social.

Isso não quer dizer que a teoria social tenha que ser uma teoria da ação (Stichweh, 2000a, p. 5-13). O agir e o vivenciar sociais são compreendidos por uma teoria dos sistemas como constelações de atribuição de sentido que servem à observação de operações comunicativas por meio de operações comunicativas. A depender de como uma ação social apareça para um observador, "podem variar os estímulos para a construção de sentido e, assim, para a construção de uma semântica que possa registrar, organizar e tornar acessíveis determinadas experiências sociais de sentido" (Luhmann, 1980, p. 22).

Em um momento posterior de sua formulação, Luhmann define o par conceitual estrutura/semântica não apenas como consequência da repetição e condensação de sentido, mas a partir da distinção entre operação e observação. Segundo ele, "a comunicação só pode ser compreendida como operação de observação", por meio da qual ela reproduz a diferença indispensável entre informação e mensagem (Luhmann, 1997, p. 538). As operações observam e reproduzem o sistema social enquanto ocorrem. A diferença entre operação e observação corresponde, assim, na teoria dos sistemas, à existência de dois níveis de estruturas: aquele que se refere à estrutura de diferenciação (as possibilidades concretas de ação em uma sociedade) e aquele que se refere às semânticas capazes de tornar o sentido identificável, fixando-o e possibilitando a sua lembrança ou esquecimento (Luhmann, 1997, p. 538). As observações são o lado da operação que produz uma estrutura de caráter especial: as semânticas. Mas a semântica também dispõe de operatividade dentro de um sistema 
social, já que observações "são operações cuja realidade se demonstra na rede operativa recursiva de sentido do próprio sistema social" (Luhmann, 1997, p. 538). Assim, tanto semântica como estrutura são estruturas ao mesmo tempo operativas e observacionais.

Mas, se toda a comunicação acontece no meio sentido, e se toda a comunicação - já as palavras - produz operativamente sentido condensado e confirmado que também consiste em observações, por que então insistir na diferença, aparentemente um tanto esotérica, entre estrutura e semântica? Toda estrutura não seria semântica, assim como toda semântica não seria também uma estrutura? Não se trataria tudo de comunicação? Não coincidiria nisso a teoria dos sistemas com outras teorias pós-estruturalistas do discurso (Stäheli, 1998a, p. 331)? Ainda assim, um exame cuidadoso da teoria demonstra que essa é uma de suas distinções mais utilizadas e mais importantes (Stichweh, 2000, p. 237).

Com efeito, a diferença estrutura/semântica é também um artefato semântico da observação da sociologia, que é um subsistema do sistema científico, subsistema da sociedade global que ela descreve. Se a sociologia é uma forma de comunicação que produz o próprio objeto ao descrevê-lo por meio de diferenças (semânticas) como sistema/ambiente, operação/observação e estrutura/semântica, certamente seria equivocado definir aquela diferença a partir da distinção realidade/linguagem, como no caso da história dos conceitos. Ela permanece, portanto, uma distinção discursiva (e pós-estruturalista). Ao mesmo tempo, sua utilidade teórica consiste, exatamente, em que ela é um correlato - um equivalente funcional - pós-estruturalista de diferenças como real/simbólico, acontecido/concebido (em conceitos) e infraestrutura/superestrutura (Basis/ Überbau). A partir da diferença estrutura/semântica, a sociedade emerge como observadora de si mesma, fazendo-a por meio de uma comunicação (semântica) sobre sua própria comunicação (estrutura). A diferença se 
contém a si mesma, já que é também uma semântica (Luhmann, 1992, p. 11): isso faz dela uma forma paradoxal de observar a sociedade, que apenas sociedades extremamente complexas podem suportar e que precisa ser temporalizada na forma de uma teoria social construtivista sempre aberta a novas observações.

Essa redefinição conceitual realizada pela teoria dos sistemas da diferença estrutura/semântica tem razões próprias e implicações diversas para a compreensão da sociedade. Em primeiro lugar, o fato de que a diferença semântica/estrutura toma o lugar da diferença realidade/discurso implica um contínuo e - talvez - infinito deslocamento de perspectivas de observação: ela significa um rompimento com a limitação à perspectiva de observação de primeira ordem, levando a uma descrição da sociedade como resultado de operações sociais que também são observações e que estão sempre sujeitas a outras e diversas ordens de observação de segunda ordem. ${ }^{1}$

Essa transformação leva a uma segunda consequência radical: a realidade da teoria dos sistemas se fragmenta em tantas realidades quantos forem os observadores. A distinção - semântica - entre estrutura/ semântica torna-se um resto de realismo a possibilitar que uma teoria da complexidade descreva as formas pelas quais a sociedade multiplica, estruturalmente, as realidades que constitui em si e para si mesma. Graças à diversidade de sistemas sociais que observam o seu meio ambiente de acordo com a sua respectiva semântica, em uma sociedade supercomplexa, funcionalmente diferenciada, a realidade do direito não é a mesma realidade da ciência, da política ou da educação. E como, mesmo para cada um desses sistemas, a realidade construída internamente se altera no tempo, na medida em que a sua semântica social também se altera, a única semântica capaz de descrever essa estrutura é uma semântica da complexidade. Uma argumentação em círculo que revela o caráter

\footnotetext{
${ }_{1}^{1}$ Nisso reside "a invisibilidade inevitável do mundo" (Luhmann, 1997, p. 1113).
} 
tautológico de uma sociedade que não pode contar com um critério último para a observação da realidade social e que só pode contar com seus próprios mecanismos, construídos socialmente, de autodescrição.

A teoria do observador de segunda ordem implode, desse modo, com a distinção sujeito/objeto, sem que, por isso, a observação sociológica precise ser compreendida como uma tarefa completamente aleatória (Luhmann, 2005, p. 221). Em lugar disso, a teoria dos sistemas entende que o real, o necessário e também o contingente são formas pelas quais cada sistema social opera e observa. E as formas por meio das quais os sistemas sociais as utilizam depende da especificidade de suas estruturas, que podem ser reconstruídas sociologicamente.

Como outras teorias pós-estruturalistas fundadas na análise do discurso prescindem, em grande medida, de uma teoria da observação de segunda ordem, elas insistem em perspectiva que vê a realidade como resultado de um processo evolutivo cego, que ignora a distinção entre níveis de complexidade, relações evolutivas de probabilidade e comparações funcionais. Ao mesmo tempo, como prescindem de qualquer referencial social para definir a correção das próprias observações (toda a linguagem é descrita como reprodução indistinta de relações de poder), teorias como a de Michel Foucault têm que insistir, por exemplo, em conceitos como o de "resistência" (Foucault, 1999, p. 91) ou em diferenças como poder e corpo $^{2}$, capazes de oferecer um ponto de vista com que julgar (normativamente) o "voo cego" da evolução dos dispositivos de poder, ao mesmo tempo em que se abstém de explicá-los (Foucault, 1982, p. 4950; Dreyfus; Rabinow, 1982, p. 44). Outra opção, comum entre teorias desconstrucionistas, é simplesmente afirmar que o discurso se reproduz

${ }^{2}$ Essa busca pelo corpo se tornou uma tendência bastante usual em abordagens inspiradas por Michel Foucault. Dever-se-ia, talvez, antes de tudo, buscar uma definição de corpo. Sobretudo se se o define como elemento fundamental de relações de poder (Foucault, 1982, p. 55-63). Para Luhmann o corpo é um mecanismo simbiótico, cujo sentido é definido pela comunicação (Luhmann, 1981). 
por meio de distinções que excluem o "distinguido", numa interminável sequência de exclusões. As exclusões restam, porém, sem qualquer especificação teórica capaz de explicar reconstrutivamente os processos históricos e sociais contingentes que lhes deram lugar.

Em oposição a isso, a teoria dos sistemas introduz a diferença entre estrutura e semântica, a partir da distinção entre observador de primeira e de segunda ordem (ou de $n$ ordens). A partir dela, a realidade aparece sempre de modo ontológico para um observador de primeira ordem, o qual sempre pode ser submetido a uma nova observação, que relativiza a ontologização de primeiro nível, observando suas condições de possibilidade e sua contingência. A observação de segunda ordem, por sua vez, também está exposta a novas observações, realizadas de acordo com outros pontos de vista (Luhmann, 2004, p. 140). O lugar da observação sociológica é o de observador desde uma perspectiva que leva em conta a complexidade social estruturante como condicionante da observação de cada observador de primeira ordem, seja ele um "sujeito", uma organização ou um sistema funcional. Para isso, ela trabalha com uma distinção teórica entre um nível descrito e um nível que descreve. Isso nos leva a refletir sobre a aproximação da teoria dos sistemas com a tradição materialista da teoria social.

\section{Estrutura e semântica como forma de observação da evolução social: seria a teoria dos sistemas materialista?}

Apesar de Luhmann, expressamente, negar uma relação direta entre a diferença estrutura/semântica e a diferença base/superestrutura (Luhmann, 1980, p. 11) com origem na tradição marxista ${ }^{3}$, pode-se perceber claramente que persistem correlações entre as duas semânticas. De fato, a forma ambígua como ele trata a distinção e a diversidade de

\footnotetext{
${ }^{3}$ Em Marx, lê-se: Com uma mudança nos fundamentos econômicos transforma-se toda a superestrutura lenta ou rapidamente (Mew, 1961, p. 9)
} 
significados do conceito de semântica na teoria dos sistemas dificulta sua compreensão. Ainda assim, um olhar cuidadoso pode desvendar a forma peculiar como aquela tradicional diferença da teoria social moderna parece ainda ressoar no funcionamento interno da teoria.

No interior da teoria dos sistemas, o problema da relação entre estrutura e semântica é abordado sobretudo por meio da teoria da evolução social. Mais precisamente, como um problema relativo à relação entre a evolução das estruturas e das semânticas sociais - a qual é tratada sob o título de "evolução das ideias" (Luhmann, 1980; 2008; 1997, p. 536-57). À medida que Luhmann, em sua formulação mais madura, passa a compreender a distinção estrutura/semântica como uma diferença correlata à diferença operação/ observação (Luhmann, 1997, p. 537), torna-se mais evidente uma separação entre dois níveis evolutivos. E essa separação parece mesmo aproximar sua formulação das velhas questões do idealismo alemão.

Tal separação se torna ainda mais evidente, quando ele inclui uma terceira distinção para auxiliar a compreensão das duas primeiras: a diferença entre observação e descrição. Com isso, a relação entre operação e observação, que era uma diferença apenas de ordem de observações (primeira e segunda ordens), transforma-se em uma diferença qualitativa. Nesse ponto, Luhmann entende que a semântica social ganha um caráter especial, quando sistemas sociais produzem um tipo de comunicação extremamente improvável e que depende de determinada complexidade: autodescrições Luhmann (1987, p. 601-2; 1997, p. 539). Ele se refere, assim, a um tipo de observação dirigida ao próprio sistema e que reflete, internamente, o problema de sua unidade. Esse nível de observação seria o nível de observação mais reflexivo a ser realizado por um sistema social, definido como o nível de observação da reflexão e distinguindo-se do nível basal (das operações estruturais) e do nível da reflexividade (que observam as operações basais) (Luhmann, 1987, p. 615-20). Nele 
produz-se informação "sobre o que é comunicado, quando a sociedade comunica sobre a sociedade" (Luhmann, 1997, p. 883). Dito de outro modo, a semântica condensada e confirmada em cada nível pode ser observada internamente por uma autodescrição reflexiva produzida pelo próprio sistema, como uma teoria do sistema sobre si mesmo (Luhmann, 1997, p. 883 e ss; 1987, p. 618).

Autodescrições podem ser ainda mais diferenciadas, quando elas se revestem de forma textual e descrevem a sociedade por meio de uma teoria da reflexão. Os gregos, socialmente diferenciados a partir de uma forma estruturalmente estratificada, produziam cosmologias de acordo com as quais eles se viam como humanos (e próximos da perfeição), enquanto outras sociedades eram vistas como bárbaras. Assim como em sociedades diferenciadas funcionalmente o direito produz teorias sobre sua própria unidade (como teorias constitucionais positivas, jusnaturalistas etc.) que em muito podem divergir da forma como, por exemplo, a política, a religião ou a sociologia o observam.

Haveria, segundo Luhmann, dois níveis distintos de estruturas, cujos mecanismos evolutivos se separariam e ganhariam características próprias. Um nível reproduziria as estruturas dos sistemas sociais e outro nível descreveria essa reprodução; duas evoluções distintas: a evolução estrutural e a evolução semântica - ou das ideias. E se a semântica é compreendida como resultado de observações reflexivas, a evolução das ideias apresenta, por seu turno, uma consequente posterioridade linear em relação à evolução estrutural Luhmann (1998a, p. 330). Isso se daria porque a realidade das estruturas operativas basais teria um significado decisivo e constitutivo para a determinação da complexidade dos sistemas, determinando de forma basal a reprodução da diferença sistema/ambiente. Por seu turno, semânticas autodescritivas observariam essas estruturas, sendo, assim, de certa forma dependentes da complexidade oferecida pelas primeiras. Em 
outras palavras, a observação autodescritiva tem que ocorrer logicamente como um elemento condicionado pelo evento que observa e, embora, no caso da teoria dos sistemas, ambos os eventos possam ocorrer de forma simultânea (pois toda observação também constrói operativamente a realidade com que se relaciona de forma simultânea ao que observa), haveria uma relação de constitutividade entre estrutura e semântica (Stäheli, 2000, p. 186-207). Nas palavras de Luhmann, as autodescrições "não são operações constitutivas, mas apenas operações posteriores" de um dado sistema social (1997, p. 883).

De fato, se uma observação é uma operação, ela depende também de algo a ser observado. No caso da constituição da semântica conceitual de que dispõe um sistema para se auto-observar, tais observações teriam sempre que pressupor operações anteriores capazes de reproduzir a própria diferença entre sistema e ambiente (Fuchs, 1995, p. 15). Para usar o mesmo exemplo: se os gregos operam estruturalmente a partir de uma diferenciação estamental e hierárquica, sua autodescrição terá sempre que produzir uma noção de perfeição que seja condizente com as desigualdades estruturais entre seus sistemas sociais (os estamentos ou classes) - para os quais outras sociedades permanecem externas e, portanto, incompreensíveis, bárbaras.

Outra consequência importante dessa concepção se dá no que diz respeito à concepção de Luhmann acerca dos mecanismos da evolução semântica. A forma pela qual teorias reflexivas evoluem seria definida em confrontação com a realidade estrutural que elas descrevem e o critério de seleção evolutiva seria, em última análise, a sua "plausibilidade" (Luhmann, 1997, p. 547-50; 1980, p. 40). "Ideias são plausíveis, se elas iluminam imediatamente e não precisam ser justificadas no processo comunicativo" (Luhmann, 1997, p. 548). Embora autodescrições e teorias possam ser testadas contra si mesmas (textos teóricos anteriores selecio- 
nam, por exemplo, quais são os textos posteriores aceitáveis e inaceitáveis), em casos limite, a plausibilidade de uma ideia - e de uma autodescrição - deve ser sempre testada frente à estrutura social que descreve. O teste de plausibilidade seleciona, assim, quais os artefatos semânticos que se impõem a partir de mecanismos externos à mera produção textual no nível da reflexão. A evolução semântica passa, assim, a ser concebida como um nível evolutivo em relativa dependência do nível estrutural: uma verdadeira semântica histórica. E, com isso, temos claramente uma visão da relação entre semântica e complexidade estrutural que parece corresponder àquela de uma tradição materialista que via uma dependência de superestruturas ideológicas e semânticas da realidade social subjacente. A premissa teórica fundamental comum é a de que a operação basal da sociedade teria um significado fundamental para o curso da evolução social como um todo.

A rigidez - quase materialista - dessa concepção de evolução semântica pode ser, no entanto, relativizada. Primeiramente, poderíamos lembrar que, para a teoria dos sistemas, semânticas são ubíquas (as estruturas também são semânticas!) e elas oferecem a todo sistema, seja no nível operativo basal, da reflexividade ou da reflexão, uma prestação imprescindível para a seletividade de suas próprias estruturas. Também a produção de textos oferece condições ampliadas de tratamento interno da complexidade dos sistemas e a fixação de autodescrições permite uma capacidade imensa de selecionar aquilo que deve ser mantido ou descartado em termos de informação sobre as próprias estruturas. A memória do sistema produz, assim, lembrança e esquecimento, permitindo com que "operações sejam construídas à luz da consistência interna com as suas próprias operações" (Luhmann, 1997, 578); sua função é a de "garantir provas de consistência ao mesmo tempo em que deixa livre capacidades de processamento de informações, para que o sistema possa se abrir 
para irritações" (Luhmann, 1997, p. 580). Nesse sentido, textos podem ser produzidos para serem reconhecidos e reutilizados, com o objetivo de coordenar as observações que a eles se adaptam (Luhmann, 1997, p. 887). À medida que a sociedade produz descrições para observar suas próprias operações, a semântica ganha uma certa função normativa, de modo que textos são submetidos e comparados a textos já existentes de acordo com critérios de correção (Luhmann, 1997, p. 888). Assim, a semântica sempre também condiciona e não apenas é condicionada. E essa intuição poderia ser levada ainda mais adiante.

Foi o que tentou, por exemplo, Urs Stäheli, ao fazer uso de aportes teóricos de teorias do poder para descrever a relação entre a semântica e a estrutura. Utilizando-se do exemplo da semântica do "politicamente correto", ele argumenta que experiências, fatos e operações basais podem, muitas vezes, ocorrer sem que tornem socialmente problemáticas - e vistas como contingentes (Stäheli, 1998a; 2000, p. 214-18). Um conjunto disforme de interações e experiências pode, no entanto, ser trazido à comunicação, de formas diversas, por meio de descrições e redescrições (Umschrifte) que as dotam de uma nova operatividade no interior de um sistema social. ${ }^{4}$ Experiências podem ser vivenciadas e apenas posteriormente serem significadas como marcadas por violência, exclusão e frustração. O seu registro como humilhantes, "traumáticas", desrespeitosas por uma semântica politizadora poderia, assim, emprestar uma nova operatividade mesmo a experiências ocorridas no passado, o que poderia acarretar uma série de consequências relevantes para a operação do sistema (Stäheli, 2000, p. 218-28; p. 266-9). Essa seria uma abordagem interessante para descrever, por exemplo, uma "política da memória" ou formas de "justiça restaurativas".

Poder-se-ia dizer assim que, embora haja uma posterioridade da semântica em relação à estrutura, a segunda poderia ser posteriormente

${ }_{4}$ Nesse ponto, Stäheli faz uso da formulação de Fuchs (1995). 
"ressignificada": programas e teorias reflexivas poderiam ganhar uma "posterioridade constitutiva" em relação às estruturas sociais, "na medida em que elas atuam como uma sobredeterminação semântica das observações de operações" (Stäheli, 1998a, p. 330). Essa intuição se aproximaria bastante daquelas de teorias do poder que reivindicam a possibilidade de lutas por hegemonia do sentido de "significantes vazios" (Laclau, 1996, p. 90). Combinando as duas linguagens teóricas, poder-se-ia falar em uma luta pela hegemonia de autodescrições dos sistemas sociais (Stäheli, 2000, p. 218-23; p. 280), vista como uma "intervenção política" nos processos que observam a contingência de observações e estruturas no interior de diferentes sistemas (Stäheli, 1998b, p. 52-6).

Uma tal interpretação da diferença entre estrutura/semântica padece, porém, de alguns riscos (Holmes, 2014). Na minha compreensão, Luhmann tinha muitos bons motivos para evitar qualquer tipo de redução da descrição sociológica a alguma forma particular de comunicação, como por exemplo a comunicação sobre o poder. Qualquer tipo de politização da comunicação interna de um sistema só pode ser resultado de uma observação de segunda ordem (Holmes, 2014, p. 114-8) que é sempre o resultado semântico de determinadas estruturas sociais. Afinal, a consciência acerca da observação desconstrutiva de segunda ordem não é uma constante nas sociedades historicamente conhecidas, sendo também um fenômeno social contingente. E uma difusão de processos de politização do discurso e a própria visibilidade da contingência politizável são relativamente improváveis evolutivamente (e recentes na forma em que conhecemos). Enfim, é preciso refletir sobre quais as condições sociais estruturais que possibilitam uma semântica sensível à complexidade e que tematize contingência da comunicação na forma de uma teoria da desconstrução ou da observação de segunda ordem.

Nesse ponto, uma teoria social orientada materialmente pela complexidade consegue oferecer boas razões em sua defesa: ela observa, no 
nível estrutural da sociedade, uma variação da complexidade que se correlaciona com possibilidades semânticas de sua descrição e insiste que uma sociedade supercomplexa produz uma semântica que deve recusar simplificações descritivas da realidade que a reduzam a apenas um ponto de vista de observação. Seja ele o poder, a escassez de recursos materiais, a verdade científica etc.

4 Sociologia como semântica da complexidade: o primado do social e o objeto das ciências sociais.

Em seu programa de pesquisa para uma sociologia do conhecimento da sociedade moderna, Luhmann apontava que a complexidade das estruturas elementares do agir e do vivenciar, que por sua vez dependem diretamente da complexidade de formas de diferenciação de uma sociedade, desencadeariam determinadas semânticas sociais com elas correlatas Luhmann (1980, p. 39). Os espaços de contingência e a seletividade das estruturas fixariam, por exemplo, papeis que limitariam e condicionariam a articulação do sentido no plano social (Luhmann, 1980, p. 24); e as suas semânticas sociais correlatas explicitariam aquilo que a sociedade entende como "objetividade, temporalidade e socialidade" (Luhmann, 1980, p. 39). Tal formulação, que inegavelmente nos lembra intuições do materialismo histórico, carece, porém, de esclarecimentos.

Primeiramente, é importante lembrar que, para Luhmann, a complexidade não é definida apenas a partir da "quantidade de elementos" e da "diversidade de relações" entre eles, como usualmente feito por outras abordagens teóricas (Luhmann, 1975, p. 257). Para ele, o conceito de complexidade tem que ser compreendido em associação com o conceito de sistema. Assim, a complexidade social depende de uma seletividade entre as estruturas internas de um sistema, capaz de selecionar de modo 
estável as possibilidades de relação entre seus elementos à medida que essas possibilidades aumentam (Luhmann, 1975, p. 258). A incapacidade de fazê-lo pode custar a um sistema sua própria existência. Complexidade é assim "uma mistura entre redundância e variedade", ela consiste em uma paradoxal "unidade da diversidade" (Luhmann, 1997, p. 136). Isso quer dizer que a complexidade de um sistema social depende das estruturas que selecionam, dentro da variedade, um conjunto de possibilidades como mais prováveis, excluindo uma diversidade de outras possibilidades, como improváveis. "Com o crescimento positivo de elementos cresce a seletividade negativa que elimina outras relações não realizáveis" (Luhmann, 2009, p. 258). A seletividade das estruturas ao mesmo tempo aumenta a contingência e diminui a aleatoriedade das relações estruturais. E isso torna a continuidade da existência do sistema mais provável.

A diferenciação sistêmica é, por sua vez, uma "promotora de complexidade e um gatilho para a formação de ordens sociais emergentes" (Luhmann, 1980, p. 21). Essa "promoção da complexidade" se dá como consequência do fato de que a diferenciação sistêmica de uma sociedade dá azo à diversidade de formas de ação no interior da sociedade global. Diferenciação sistêmica indica, nesse contexto, o fato de que, no interior de um sistema social, novas diferenças entre sistema e meio ambiente emergem, constituindo novas dinâmicas autopoiéticas de reprodução da comunicação - subsistemas - para as quais os demais subsistemas sociais aí operativos permanecem como meio ambiente (Luhmann, 1997, p. 597).

Já a forma de diferenciação define o modo como as relações entre os subsistemas se organizam; ela determina, por exemplo, como e quando a observação e a operação de um subsistema social condicionam a operação ou auto-observação de um outro subsistema. A forma de diferenciação determina a formação de normas, a diferenciação de sistemas sociais emergentes e, obviamente, as autodescrições desses sistemas (Luhmann, 
1997, p. 610). Fala-se, por sua vez, no "primado" de uma determinada forma de diferenciação, "quando se pode afirmar que uma determinada forma de relação regula as outras possibilidades de relação" entre os sistemas sociais em uma determinada sociedade (Luhmann, 1997, p. 612). ${ }^{5}$ Isso nos traz a pergunta sobre que tipo de autodescrição as sociedades podem produzir, a depender da sua forma primária de organizar a complexidade. Em outras palavras: quais são os traços semânticos característicos de formas distintas de diferenciação sistêmica?

Desde sua perspectiva, Luhmann argumenta que "apenas poucas formas de diferenciação se formaram na história das sociedades" (Luhmann, 1997, p. 612). Tais formas podem ser ditas limitadas por algumas leis gerais de possibilidade, embora não seja possível enumerá-las taxativamente. ${ }^{6}$ Seguindo de modo heurístico a tradição da antropologia estruturalista, Luhmann descreve quatro formas básicas de diferenciação: (a) a diferenciação segmentar, baseada na igualdade entre os elementos (subsistemas sociais), que se organizam a partir da descendência ou da comunidade de moradia, dividindo-se em subsistemas em grande medida simétricos entre si; (b) a diferenciação entre centro e periferia, que permite uma diferença fundada na desigualdade entre os subsistemas sociais, que lhes atribui uma posição de proeminência à medida em que se localizam no que é socialmente designado como o centro; (c) a diferenciação estratificada, organizada a partir de uma desigualdade rígida ou uma hierarquia entre seus subsistemas - normalmente estruturados

\footnotetext{
${ }^{5}$ Isso não significa que a evolução social implique necessariamente um aumento contínuo de complexidade. Variações de complexidade são resultados laterais de mudanças na diferenciação sistêmica e derivam da própria contingência temporal da operação dos sistemas sociais, que podem se adaptar ou perecer: sistemas sociais são sempre máquinas históricas - ou máquinas não triviais, no sentido de Heinz von Foerster (Luhmann, 1997, p. 570).

${ }^{6}$ Nesse ponto, a teoria dos sistemas se diferencia claramente do funcionalismo estruturalista de teorias como a de Talcott Parsons, para quem as funções de uma sociedade são dadas de antemão. Para a teoria dos sistemas, cada sistema produz a sua própria função como resultado de processos contingentes de seleção.
} 
como estamentos ou classes; e, por fim, (d) a diferenciação funcional, que admite simultaneamente a desigualdade e a igualdade entre seus subsistemas, de modo que cada um deles se estrutura de acordo com a sua própria lógica operativa (sendo portanto distinto) sem que, de antemão, prevaleça ou tenha preferência em relação aos outros (Luhmann, 1997, p. 613).

Para os interesses do presente trabalho, não precisamos revisar cada uma dessas formas e suas implicações semânticas. Basta-nos apontar que formas menos complexas vão permitir menos visibilidade de contingência, estruturando uma convergência do sentido para a sua dimensão social. Ao mesmo tempo, formas mais complexas tendem a diferenciar as esferas social, temporal e objetiva do sentido (Nassehi, 2008 p. 247). ${ }^{7}$ Para entender essa afirmação, podemos reconstruir a transição entre formas estratificadas de diferenciação e a forma de diferenciação funcional típica da sociedade mundial atual.

Para a teoria dos sistemas, uma sociedade organizada com base no primado de diferenças hierárquicas - apoiadas em formas de estratificação que distribuem os seres humanos em subsistemas sociais desiguais entre si, normalmente por nascimento, na forma de estamentos ou classes sociais rígidas - desencadearia a emergência de descrições da vida social compatíveis com a reprodução dessas hierarquias (Luhmann, 1980, p. 26). A semântica autodescritiva característica de sociedades estratificadas seria baseada em distinções ontológicas e o exemplo mais explorado por Luhmann é aquele que ele denomina a semântica velha-europeia, fundada na separação metafísica entre o ser e o não ser (Luhmann 1997, p. 895). Com efeito, do ponto de vista meramente lógico, essa semântica

\footnotetext{
7 É importante lembrar que complexidade nada tem a ver com qualquer diferença entre avançado ou atrasado, desenvolvido ou subdesenvolvido, civilizado ou pré-civilizado. A complexidade social diz respeito apenas à diferenciação de elementos sociais e ao aumento da contingência das possíveis relações entre esses elementos.
} 
é altamente plausível, pois que apenas o ser é, e o não ser não é. Mas o que fazer se houver divergência entre observações diversas do ser (Rasch, 2009, p. 89)? A objetividade, que emerge como a convergência entre as observações diversas, ganha a dimensão normativa de uma restrição ontológica: o postulado do conhecimento verdadeiro é apoiado no fato de que ele representa o mundo como ele é (Rustermeyer, 2007, p. 505). Mas, com isso, a pergunta é apenas deslocada: afinal, quem ou o que decide sobre a objetividade? (Ou sobre a realidade do ser?) Essa distinção se estruturaria então em uma diversidade de formas secundárias como, por exemplo, na distinção entre sujeito/objeto ou mesmo realidade/representação. Dever-se-ia sempre atribuir a uma concepção de sujeito, a uma classe de pessoas ou a uma lógica particular a capacidade de estabelecer, de modo seguro e último, a segurança da distinção.

Para Luhmann, esse tipo normativo de diferenciação semântica corresponderia à necessidade de reprodução de instâncias sociais capazes de decidir, em última análise, como distinguir - ou representar - a realidade. As sociedades podem resolver esse problema, por exemplo, de forma teológica e atribuir a segurança da distinção a uma instância omnisciente, capaz de funcionar como supervisora última de toda observação social (Rasch, 2009, p. 90). Essa entidade funcionaria como único observador de segunda ordem, um observador absoluto, e a sua posição corresponderia semanticamente aos constrangimentos estruturais de uma sociedade radicalmente hierárquica. Essas estruturas sociais desencadeariam, assim, a emergência de semânticas sociais que garantem a certeza das autodescrições. Algo que encontraria correlação estrutural na existência de instâncias sociais a partir das quais a sociedade é reproduzida, supervisionada e controlada, de acordo com a sua hierarquia: uma corte aristocrática ou clerical, a cidade etc. Essas instâncias estruturais têm que poder contar afinal com os artefatos semânticos que garantam a reprodução de sua posição, uma condição para a própria estabilidade de todo o sistema social. 
Luhmann está consciente de que a palavra "ontologia" surge apenas no século XVII, como objeto de uma crítica à metafísica, proveniente da crescente reflexão epistemológica da ciência moderna emergente. Ainda assim, ele afirma que a reflexão epistemológica, de Kant a Hegel, de Marx a Adorno e Horkheimer, não é mais do que uma semântica de transição, que desloca a posição do observador último de sua dimensão teológica para uma dimensão lógica, fundada na subjetividade, na dialética ou na história. ${ }^{8}$ Essas formas de reflexão não fariam mais do que substituir o Deus-criador pelas leis do pensamento (ou pelas leis da história), sendo o resultado de uma estrutura social que estaria em franca transição, testemunhando a ascensão do individualismo moderno e de novas formas políticas e sociais como resultado da crescente diferenciação funcional da sociedade mundial. Uma semântica que teria dificuldades em lidar com a ausência de um ponto arquimédico de observação e que tenta, portanto, reintroduzi-lo por outros meios.

A estrutura social de uma sociedade funcionalmente diferenciada é baseada numa diversidade crescente de subsistemas sociais, cada um deles operando com referência a um problema - a produção econômica, a possibilidade de decisões coletivas, a estabilização de expectativas normativas, a pesquisa científica etc. "Funções desse tipo não podem ser trazidas à forma de uma ordem hierárquica válida de modo universal", pois, mesmo que algumas delas possam prevalecer em dadas circunstâncias, cada uma delas é igualmente indispensável e, num primeiro momento, insubstituível pelas outras (Luhmann, 1980, p. 27). A reprodução da ciência moderna precisa da economia a lhe dar os meios de produção, assim como a economia necessita do Estado, que necessita do direito etc. De forma diferente do que ocorre em sociedades estratificadas, em que subsistemas se orientam a partir de uma única semântica dominante,

${ }^{8} \mathrm{E}$, por que não no transcendental pragmático de uma ética do discurso, no caso de Jürgen Habermas? Ver: Luhmann, 2005. 
cada sistema funcional constrói sua própria identidade. Cada um deles "destroça a unidade da sociedade global em uma diferença específica entre sistema e meio ambiente, ou entre o subsistema e o meio ambiente social interno da sociedade" (Luhmann, 1986, p. 204). Eles passam, assim, a observar autorreferencialmente a si mesmos - de modo reflexivo - e à sociedade a partir da sua diferença definitória (Luhmann, 1997, p. 757). O direito observa a partir do código lícito/ilícito, a economia a partir do código dinheiro e da diferença ter/não-ter, a arte a partir da diferença belo/feio, a ciência como verdade/falsidade etc. Mas nenhuma dessas perspectivas tem de antemão prevalência e a isso Luhmann chama, apoiando-se em Gottard Günther, policontexturalidade (Luhmann, 2000; 1990, p. 634; 1997, p. 36).

O problema de uma descrição da sociedade funcionalmente diferenciada é que descrevê-la consiste, necessariamente, em escolher um ponto de vista de observação para o qual não existe nenhuma garantia de exclusividade (Rasch, 2009, p. 102). Não há nenhum método axiomático que funde uma explicação primeira e ofereça uma garantia última de validade em um contexto de policontexturalidade. Mas, então, resta um lugar para a sociologia como teoria da sociedade? Esse não seria o ponto em que teria emergido uma semântica da pós-modernidade, que abre mão de qualquer relação entre discurso e realidade, e deixa a sociedade sem nenhuma garantia sobre si mesma, um contexto em que anything goes (Luhmann, 1992, p. 13)?

$\mathrm{Na}$ abertura de "Observações da Modernidade", Luhmann insiste em que gostaria de começar sua "análise da modernidade da sociedade contemporânea fazendo uma distinção entre a sua estrutura social e sua semântica" (Luhmann, 1992, p. 11). Caberia à sociologia, segundo ele, ir além da frustração da semântica pós-moderna com a pluralidade, cujas raízes estariam na perplexidade da cultura europeia com a obsolescência 
de suas velhas semânticas. Para isso, ela deveria levar a sério as estruturas que multiplicariam as formas de observação social (Luhmann, 1992, p. $17 \mathrm{~s})$. Esse seria seu objeto de investigação: observar e comparar a emergência e operação dos sistemas funcionais, sem reduzir suas lógicas umas às outras com base em decisões pré-teóricas. Levando em conta, portanto, a sua contingência.

Contingência, no entanto, não quer dizer arbitrariedade ou relativismo total. A reconstrução sociológica das estruturas sociais da sociedade funcionalmente diferenciada aponta a razoável estabilidade evolutiva de certas distinções, que ganham uma probabilidade de manutenção extremamente alta. As estruturas da diferenciação funcional são o resultado de processos de seleção que as tornam altamente estáveis. É difícil, por exemplo, evitar a comunicação científica, se se quer comunicar sobre expectativas cognitivas. Assim como seria difícil pensar a ciência sem teorias, métodos, publicações e estruturas de reflexão do código verdade/falsidade. E é muito difícil conseguir alguma estabilidade de expectativas normativas sem se recorrer a estruturas jurídicas de produção de normas sociais. Ou pensar o exercício do poder sem o Estado.

Mas uma teoria social da complexidade pode observar a contingência até mesmo dessas "estruturas estáveis". É possível, por exemplo, comparar as funções, reconstruindo as probabilidades e improbabilidades de serem substituídas por outras. Certamente, pode-se pensar numa substituição do direito ou da economia por outras formas de operação: já houve inclusive experimentos em que se tentou substituí-los pela política, como no caso de alguns regimes totalitários do século XX. A sociedade moderna permite até mesmo a projeção de uma "sociedade alternativa", a qual, porém, permanece apenas como uma imaginação irrealizável enquanto não se consubstanciar em diferenças operativas com capacidade real de substituir aquelas efetivamente em uso. Substituições precisam, 
afinal, tornar-se estruturais para ir além da mera imaginação e da consciência sobre a contingência. Sociedades dificilmente abandonam uma estrutura por nenhuma outra. "Só podemos nos mudar, quando achamos um novo apartamento" (Luhmann, 1992, p. 47). E essas novas estruturas estão sempre sujeitas a novas seleções.

Uma teoria dos sistemas sociais, apoiada numa semântica da complexidade, faz uso da distinção estrutura/semântica para garantir uma observação material das estruturas sociais que empreste plausibilidade às distinções de que se utiliza para observar a sociedade. Mas ela não acredita que essa materialidade está sujeita a uma ordem, lógica ou dinâmica intrínseca única (seja o trabalho, a luta de classes, a racionalidade decisória, a luta por reconhecimento ou a liberação da ação comunicativa). Há nela uma tentativa de associar o materialismo da descrição sociológica com o pós-estruturalismo que atribui à dinâmica recursiva da comunicação a construção das estruturas sociais, assim como do próprio conhecimento sobre elas. Essa teoria insiste, assim, em que uma sociedade complexa será descrita de forma mais plausível por uma teoria que leve em conta toda sua complexidade, pois esta é também a condição material de operação da própria teoria.

Pablo Holmes é Doutor em Sociologia e professor do Instituto de Ciência Política (UnB) e do Programa de Pós-Graduação da Faculdade de Direito da Universidade de Brasília-UnB.\pabloholmes@unb.br 


\section{Referências}

1. DREYFUS, Hubert; RABINOW, Paul. Michel Foucault: Beyond structuralism and hermeneutics. Chicago: University of Chicago, 1982.

2. FOUCAULT, Michel. Power/Knowledge: Selected interviews and Other Writings 1972-1977 (Ed. Colin Gordon). Nova lorque: Pantheon, 1980.

3. FOUCAULT, Michel., A história da sexualidade. Vol. I - A Vontade de Saber. Rio de Janeiro, Graal, 1999.

4. FUCHS, Peter. Die Umschrift. Frankfurt: Suhrkamp, 1995.

5. HOLMES, Pablo. Verfassungsevolution in der Weltgesellschaft: Differenzierungsprobleme des Rechts und der Politik im Zeitalter der Global Governance. Baden-Baden: Nomos, 2013

6. HOLMES, Pablo. Die politische Differenz und die Systemtheorie: Probleme einer soziologischen Verallgemeinerung machttheoretischer Unterscheidungen. Soziale Systeme, v. 19, n. 1/2, p. 110-26, 2014.

7. KOSELLECK, Reinhardt. Einleitung. In: BRUNNER, Otto; CONZE, Werner; KOSELLECK, Reinhart (Hg.), Geschichtliche Grundbegriffe, Historisches Lexikon zur politisch-sozialen Sprache in Deutschland. Vol. 1. Stuttgart: Ernst Klett Verlag, pp XIII-XXVII, 1972.

8. KOSELLECK, Reinhardt. Vergangene Zukunft: Zur Semantik geschichtlicher Zeiten. Frankfurt: Suhrkamp, 1995.

9. KOSELLECK, Reinhardt. Begriffsgeschichten. Studien zur Semantik und Pragmatik der politischen und sozialen Sprache. Frankfurt, Suhrkamp, 2006

10. LACLAU, Ernesto. Emancipation(s). Londres: Verso, 1996.

11. LUHMANN, Niklas. Komplexität. In: LUHMANN, Niklas. Soziologische Aufklärung 2: Aufsätze zur Theorie der Gesellschaft. Wiesbaden: VS Verlag, 1975, pp. 255-76.

12. LUHMANN, Niklas. Gesellschaftliche Struktur und semantische Tradition. In: LUHMANN, Niklas. Gesellschaftsstruktur und Semantik. Studien zur Wissenssoziologie der modernen Gesellschaft. Vol. I. Frankfurt: Suhrkamp, 1980.

13. LUHMANN, Niklas. Symbiotische Mechanismen. In: LUHMANN, Niklas. Soziologische Aufklärung. Vol. 3. Wiesbaden: VS Verlag, 1981, pp. 228-44.

14. LUHMANN, Niklas. Ökologische kommunikation. Kann die moderne Gesellschaft sich auf ökologische Gefährdung einstellen?. Wiesbaden: VS Verlag, 1986. 
15. LUHMANN, Niklas. Soziale Systeme. Frankfurt: Suhrkamp, 1987.

16. LUHMANN, Niklas. Erkenntnis als Konstruktion, Berna: Benteli, 1988.

17. LUHMANN, Niklas. Wissenschaft der Wissenschaft. Frankfurt: Suhkamp, 1990.

18. LUHMANN, Niklas. Beobachtungen der Moderne. Opladen: Westdeutscher Verlag, 1992.

19. LUHMANN, Niklas. Die Gesellschaft der Gesellschaft. Frankfurt: Suhrkamp, 1997.

20. LUHMANN, Niklas. Einführung in die Systemtheorie. Heidelberg: Carl Auer, 2004.

21. LUHMANN, Niklas. Ich sehe was, was Du nicht siehst. In: LUHMANN, Niklas. Soziologische Aufklärung 5: Konstruktuvistische Perspektiven, Wiesbaden: VS Verlag, 2005, pp. 220-6.

22. MARX, Karl; ENGELS, Friedrich. Zur Kritik der politischen Ökonomie. In: MEW, Band 13, 1961.

23. NASSEHI, Armin. Die Zeit der Gesellschaft: Auf dem Weg zu einer soziologischen Theorie der Zeit. Wiesbaden: VS Verlag, 2008.

24. RASCH, William. Luhmann's ontology. Revue Internationale de Philosophie, v. 259, n. 1, p. 85-104, 2012.

25. RUSTERMEYER, Dirk. Die Logik der Form und das Problem der Metaphysik. Soziale Systeme, v. 13, n. 1+2. Stuttgart, p. 504-15, 2007.

26. STÄHELI, Urs. Die Nachträglichkeit der Semantik, Zum Verhältnis von Sozialstruktur und Semantik, Soziale Systeme, v. 4, n. 2, Stuttgart, p. 315-40, 1998a.

27. STÄHELI, Urs. Politik der Entparadoxierung. Zur Artikulation von Hegemonieund Systemtheorie. In: MARCHART, Oliver (Org.). Das Undarstellbare der Politik. Zur Hegemonietheorie Ernesto Laclaus. Wien: Turin + Kant, p. 52-66. 1998b.

28. STÄHELI, Urs. Sinnzusammenbrüche: Eine deskonstrutivistische Lektüre Niklas Luhmanns Systemtheorie. Weilerwist: Vellbrücke, 2000.

29. STICHWEH, Rudolf. Semantik und Sozialstruktur, Zur Logik einer systemtheoretischer Unterscheidung. Soziale Systeme, v. 6, n. 2, Stuttgart, p. 237-50, 2000.

30. STICHWEH, Rudolf. Systems Theory as an Alternative to Action Theory? The Rise of Communication as a Theoretical Option, Acta Sociologica, n. 43, n. 5, p. 5-13, 2000.

Recebido: 23.03.2016 